\title{
INTERFERÊnCias MÚtuas entre a Cultura do Milho, Espécies Forrageiras e Plantas Daninhas em um Sistema de Consórcio. II - IMPLICAÇÕES SOBRE AS ESPÉCIES FORRAGEIRAS ${ }^{1}$
}

\author{
Mutual Interferences Among Corn Crop, Forage Species and Weeds under a Consortium System. \\ II - Implications on Forage Species
}

SEVERINO, F.J. ${ }^{2}$, CARVALHO, S.J.P. ${ }^{3}$ e CHRISTOFFOLETI, P.J. ${ }^{4}$

\begin{abstract}
RESUMO - Esta pesquisa foi desenvolvida com o objetivo de avaliar as conseqüências da utilização de um sistema de consórcio sobre o crescimento e a conseqüente produção final de massa fresca das plantas forrageiras intercaladas à cultura do milho. Os tratamentos resultaram da combinação entre três niveis do fator espécies forrageiras (Brachiaria decumbens, Brachiaria brizantha e Panicum maximum) e três niveis do fator plantas daninhas (Ipomoea grandifolia - corda-de-viola, Amaranthus hybridus - caruru-roxo e Digitaria horizontalis - capim-colchão). Acrescentou-se, também, uma testemunha absoluta, ou seja, as espécies forrageiras crescendo sem a cultura do milho e sem plantas daninhas. Durante a condução do experimento, avaliou-se a área foliar $\left(\mathrm{cm}^{2}\right.$ por planta), a massa seca (g por planta) e o acúmulo total final de massa fresca ( $\left.t \mathrm{ha}^{-1}\right)$ das espécies forrageiras quando submetidas aos diferentes tratamentos. De forma geral, $B$. decumbens foi a forrageira menos eficiente quanto à habilidade de competição interespecífica, $P$. maximum foi a espécie que mais produziu massa fresca, enquanto $B$. brizantha foi a mais competitiva com as plantas daninhas, podendo-se inferir que estas foram as espécies menos prejudicadas pelo sistema adotado. Como conclusão geral, a pesquisa demonstrou a viabilidade da utilização do sistema de consórcio.
\end{abstract}

Palavras-chave: integração lavoura-pecuária, sistemas de manejo, competição, crescimento.

\begin{abstract}
This work aimed to evaluate the consequences of adopting a living mulch system on the growth and final fresh weight yield of forage grasses intercropped with corn crop. The treatments resulted from a combination of three levels of the factor forage species (Brachiaria decumbens, Brachiaria brizantha and Panicum maximum) and three levels of the factor weeds (Ipomoea grandifolia, Amaranthus hybridus and Digitaria horizontalis). An absolute check was also included (forage species growing without corn crop and without weeds). During the experiment, leaf area ( $\mathrm{cm}^{2}$ per plant), dry weight (g per plant) and final total fresh weight yield ( $\left.t \mathrm{ha}^{-1}\right)$ of the forage species were evaluated, when submitted to the different treatments. It was observed that B. decumbens was the least efficient forage species in relation to inter-specific competition; $\boldsymbol{P}$. maximum was the species that produced the most fresh weight, while B. brizantha was the most competitive against the weeds. It could be inferred that $\boldsymbol{P}$. maximum and B. brizantha were the species least damaged by the system adopted. It can be concluded that this work has demonstrated the viability of adopting this living mulching system.
\end{abstract}

Keywords: living mulch system, management systems, competition, growth.

1 Recebido para publicação em 4.5.2005 e na forma revisada em 24.2.2006.

Parte da tese do primeiro autor apresentada à ESALQ para obtenção do título de Doutor em Agronomia.

2 Eng.-Agr., Dr. - Coordenadoria de Assistência Técnica Integral - CATI. ${ }^{3}$ Eng.-Agr., Bolsista FAPESP, Mestrando em Fitotecnia - ESALQ/USP. <sjpcarvalho@yahoo.com.br> ${ }^{4}$ Professor Associado do Departamento de Produção Vegetal ESALQ/USP, Caixa Postal 09, 13419-900 Piracicaba-SP, <pjchrist@esalq.usp.br>. 


\section{INTRODUÇÃO}

As inovações tecnológicas para o controle de plantas daninhas na cultura do milho contemplam basicamente: conhecimento da dinâmica do banco de sementes que sustenta o recrutamento da população de plantas daninhas; aplicação de herbicidas em condição de pós-emergência; utilização de herbicidas juntamente com outros pesticidas; integração da cultura do milho com a produção de forrageiras destinadas à pecuária; e necessidade do produtor de estar devidamente informado sobre todas as possibilidades e alternativas de medidas de controle das plantas daninhas (Christoffoleti \& Mendonça, 2001).

A integração entre lavouras anuais e pastagens, ou mesmo leguminosas, tem surgido como uma alternativa para a recuperação dos solos degradados pela atividade agropecuária e se apresentado como opção na obtenção de renda extra, além de promover efeitos benéficos na cultura subseqüente. Bons resultados na produtividade da soja e no ganho de peso dos animais têm sido alcançados em sistema integrado proposto pelo Instituto de Pesquisa do Estado do Paraná (IAPAR). Neste sistema, manejam-se duas áreas: uma destinada a piquetes e outra a cultivos anuais, como soja, milho etc. O gado permanece em piquetes e, no inverno, é transferido para as áreas de cultivos anuais (Bulisani et al., 1987; Colozzi Filho et al., 2000).

Na integração agricultura-pecuária, tornase mais fácil a produção de forragem na época mais crítica do ano, isto é, no período de seca, tanto para pastejo quanto como suplemento de feno e silagem (Broch et al., 1997). Ainda, de acordo com os autores, a integração agricultura-pecuária viabiliza o desenvolvimento de duas atividades e promove a rotação de culturas, a qual, além de contribuir para a produtividade do solo, é essencial na viabilização do plantio direto.

A interferência das forrageiras no estado nutricional das culturas, bem como no rendimento de grãos, depende das condições de solo e clima, dos cultivares utilizados e do manejo empregado (Silva et al., 2004). Sistemas consorciados são viáveis quando as plantas associadas possuem período de crescimento similar, porém com picos de demandas de nutrientes em fases distintas. Assim, torna-se possivel atender às exigências das diferentes espécies sem exceder a taxa máxima pela qual os nutrientes podem ser supridos pelo solo (Willey, 1979).

A recomendação da cobertura vegetal nos agroecossistemas atém-se basicamente ao sistema de produção vigente em uma situação agrícola específica, devendo-se considerar, entretanto, a não-interferência com as principais atividades agropecuárias da propriedade; o custo dessa prática; a disponibilidade de sementes; e a preferência do agricultor (Wutke, 1993, 1998).

O conhecimento da forma como a forrageira e a cultura são afetadas em um consórcio é de fundamental importância para que haja êxito na formação e/ou na recuperação de pastagens e produção satisfatória da cultura. Silva et al. (2004) observaram que os fatores que determinam a maior competitividade entre as espécies são: porte e arquitetura da planta; maior velocidade de crescimento e maior extensão do sistema radicular; menor suscetibilidade da espécie às intempéries climáticas (como geadas e veranicos); maior índice de área foliar; e maior capacidade de produção e liberação de substâncias químicas com propriedades alelopáticas.

Dessa maneira, embora as plantas forrageiras possam ser ferramentas efetivas para o controle de plantas daninhas, elas requerem um manejo compativel, particularmente para prevenir a invasão e o estabelecimento de espécies de plantas daninhas com o tempo (Severino, 2000). Assim, o objetivo desta pesquisa foi avaliar as conseqüências da utilização do sistema de consórcio com o intuito de promover a supressão das plantas daninhas sobre o crescimento e a conseqüente produção final de massa fresca das plantas forrageiras, intercaladas à cultura de milho.

\section{MATERIAL E MÉTODOS}

O experimento foi realizado em área experimental pertencente ao Departamento de Produção Vegetal da ESALQ/USP, em Piracicaba-SP (22 $42^{\prime}$ 30” latitude sul, 47 $30^{\circ}$ longitude oeste e $546 \mathrm{~m}$ de altitude), durante o período compreendido entre os meses de dezembro de 2003 e maio de 2004. O 
solo da área experimental foi classificado como Nitossolo Vermelho (eutroférrico chernossólico) (EMBRAPA, 1999) e suas propriedades químicas estão apresentadas na Tabela 1 .

O clima da região é do tipo Cwa (Köppen, 1948), isto é, trata-se de clima mesotérmico, tropical úmido, com três meses mais secos (junho, julho e agosto) e com concentração de chuvas no verão. A temperatura média do mês mais quente é superior a $24^{\circ} \mathrm{C}$, e a do mês mais frio, inferior a $17^{\circ} \mathrm{C}$, apresentando uma pluviosidade média anual de $1.200 \mathrm{~mm}$. Os dados meteorológicos relativos ao período experimental são apresentados na Tabela 2 e foram obtidos no posto automatizado instalado no campus da ESALQ.

O experimento foi instalado em esquema de parcelas subdivididas, com delineamento experimental de blocos casualizados e três repetições. Os tratamentos são resultado da combinação entre três níveis do fator espécies forrageiras (Brachiaria decumbens - capimbraquiária - BRADC, Brachiaria brizantha capim-braquiarão - BRABR e Panicum maximum - capim-colonião - PANMA), alocadas nas subparcelas; e três niveis do fator plantas daninhas (Ipomoea grandifolia-corda-de-viola - IAGGR, Amaranthus hybridus - caruru-roxo - AMACH e Digitaria horizontalis - capimcolchão - DIGHO), alocadas nas parcelas. Acrescentou-se, também, uma testemunha absoluta, ou seja, as espécies forrageiras crescendo sem a cultura do milho e sem plantas daninhas.

Cada subparcela constou de cinco linhas de milho, espaçadas de 0,9 m entre si, intercaladas com quatro linhas das respectivas plantas forrageiras com 2,0 m de comprimento cada; portanto, uma área útil total de 7,2 $\mathrm{m}^{2}$ (3,6 $\times 2 \mathrm{~m})$. O solo foi preparado com uma roçagem seguida de uma gradagem leve na profundidade de $20 \mathrm{~cm}$, uma escarificação na profundidade aproximada de $30 \mathrm{~cm}$ e uma gradagem niveladora na profundidade média de $10 \mathrm{~cm}$.

A cultura do milho foi semeada em linhas, com semeadora tratorizada, em espaçamento de 0,90 $\mathrm{m}$ entre linhas e densidade de oito sementes por metro; o material genético de milho utilizado foi o cultivar CATI AL 34, sendo as sementes tratadas com o fungicida ftalimida

Tabela 1 - Propriedades químicas do solo da área experimental. Piracicaba, 2004

\begin{tabular}{|c|c|c|c|c|c|c|c|c|c|c|}
\hline $\begin{array}{c}\mathrm{pH} \\
\left(\mathrm{CaCl}_{2}\right)\end{array}$ & M.O. & $\mathrm{P}($ resina $)$ & $\mathrm{S}$ & $\mathrm{K}$ & $\mathrm{Ca}$ & $\mathrm{Mg}$ & $\mathrm{H}+\mathrm{Al}$ & $\mathrm{SB}$ & $\mathrm{CTC}$ & $\mathrm{V}$ \\
\cline { 2 - 10 } & $\left(\mathrm{g} \mathrm{dm}^{-3}\right)$ & \multicolumn{2}{|c|}{$\left(\mathrm{mg} \mathrm{dm}^{-3}\right)$} & \multicolumn{6}{|c|}{$\left(\mathrm{mmol}_{\mathrm{c}} \mathrm{dm}^{-3}\right)$} & $\%$ \\
\hline 5,1 & 19 & 13 & 57 & 3,8 & 40 & 12 & 28 & 55,8 & 83,7 & 67 \\
\hline
\end{tabular}

Amostra analisada no Laboratório de Análises de Solo da ESALQ/USP.

Tabela 2 - Dados meteorológicos relativos ao período de condução do experimento (dezembro de 2003 a maio de 2004). Piracicaba, 2004

\begin{tabular}{|c|c|c|c|c|c|c|}
\hline \multirow{2}{*}{\multicolumn{2}{|c|}{ Período }} & Precipitação & UR & $\begin{array}{c}\text { Temperatura } \\
\text { máxima }\end{array}$ & $\begin{array}{c}\text { Temperatura } \\
\text { mínima }\end{array}$ & $\begin{array}{c}\text { Temperatura } \\
\text { média }\end{array}$ \\
\hline & & $(\mathrm{mm})$ & $(\%)$ & & $\left({ }^{\circ} \mathrm{C}\right)$ & \\
\hline \multirow{6}{*}{2003} & Dezembro & 139,9 & 84 & 30,4 & 19,4 & 24,9 \\
\hline & Janeiro & 196,4 & 83 & 29,2 & 18,7 & 23,1 \\
\hline & "Fevereiro & 194,0 & 86 & 29,6 & 18,4 & 24,0 \\
\hline & Março & 79,1 & 83 & 29,5 & 17,3 & 23,4 \\
\hline & Abril & 92,3 & 83 & 29,0 & 17,1 & 23,0 \\
\hline & Maio & 105,9 & 89 & 24,3 & 12,8 & 18,6 \\
\hline
\end{tabular}

Fonte: Departamento de Ciências Exatas da USP/ESALQ. 
na concentração de $0,75 \mathrm{~g}$ de ingrediente ativo por quilo de sementes. A semeadura das plantas forrageiras foi feita no mesmo dia da semeadura do milho e realizada manualmente entre as linhas da cultura, utilizando-se cerca de $10 \mathrm{~kg}$ de sementes por hectare. Foi realizada uma adubação na semeadura nas doses de $30,4,106,4$ e $60,8 \mathrm{~kg} \mathrm{ha}^{-1}$ de $\mathrm{N}, \mathrm{P}_{2} \mathrm{O}_{5}$ e $\mathrm{K}_{2} \mathrm{O}$, respectivamente, e uma aplicação de nitrogênio em cobertura, aos 40 dias após a semeadura, na dose de $60 \mathrm{~kg} \mathrm{ha}^{-1}$.

A semeadura das plantas daninhas cordade-viola e caruru-roxo foi feita a lanço, seguida de incorporação com enxada, enquanto a planta daninha capim-colchão fazia parte da vegetação espontânea da área. Foram utilizados $10 \mathrm{~g}$ de sementes de corda-de-viola e $10 \mathrm{~g}$ de sementes de caruru-roxo por subparcela de $7,2 \mathrm{~m}^{2}$, sendo essa quantidade baseada em testes de emergência das sementes no campo.

As avaliações realizadas nas espécies forrageiras foram: massa fresca final $\left(t \mathrm{ha}^{-1}\right)$; acúmulo de massa seca em g por planta e acúmulo de área foliar em $\mathrm{cm}^{2}$ por planta. A massa fresca final $\left(\mathrm{t} \mathrm{ha}^{-1}\right)$ foi obtida por meio da coleta de todas as plantas incidentes em 1,0 metro linear. O local desta coleta foi selecionado ao acaso entre as três linhas centrais da subparcela, desprezando-se sua bordadura.

As avaliações de massa seca e área foliar foram realizadas em intervalos de 14 dias, iniciando aos 14 dias após a semeadura da cultura do milho, com um total de 12 avaliações. Foram colhidas três plantas em cada subparcela, ao acaso, nas três linhas centrais, cortadas na superfície do solo. A área foliar foi avaliada imediatamente após o corte, através do equipamento LICOR - LI 7000, de acordo com metodologia proposta por Benincasa (2003). As amostras foram colocadas em sacos de papel, secadas em estufa a $50{ }^{\circ} \mathrm{C}$ durante 72 horas e, posteriormente, pesadas. Os resultados utilizados na discussão representam a média das três plantas avaliadas.

Os dados de rendimento de massa fresca das plantas forrageiras foram inicialmente transformados segundo o modelo $\sqrt{\mathrm{x} \square 0,5}$, para satisfazer a necessidade de distribuição normal dos resultados. Em seguida, a variável foi analisada através da aplicação do teste F sobre a análise da variância, seguida do teste de Tukey a 5\% de significância, para comparação das médias das interações significativas.

Os resultados da área foliar e massa seca das plantas foram analisados por meio de regressões não-lineares, segundo o modelo loglogístico proposto por Seefeldt et al. (1995):

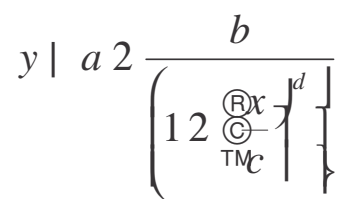

em que $y=$ variável resposta; $x=$ tempo (dias) após a semeadura do milho; $a=$ ponto mínimo da curva; $b=$ diferença entre o ponto máximo e o ponto mínimo; $c=$ tempo em dias necessário para que ocorra $50 \%$ de resposta da variável; e $d=$ declividade da curva.

\section{RESULTADOS E DISCUSSÃO}

Na Tabela 3, pode-se observar que a espécie $P$. maximum apresentou maior produção de massa fresca quando comparada com as demais forrageiras em todos os tratamentos com plantas daninhas e inclusive na testemunha, seguida das espécies $B$. brizantha e $B$. decumbens. Dentre os níveis de plantas daninhas, verifica-se que a testemunha absoluta sempre teve uma produção significativamente maior em relação ao tratamento em que se manteve a incidência de plantas daninhas e da cultura do milho (comparação dentro das linhas da tabela). No entanto, quando a analise foi feita apenas entre as plantas daninhas em estudo, observa-se que não houve diferença específica, indicando que o efeito competitivo das diferentes espécies utilizadas no experimento foi semelhante.

Pode-se verificar, também, que as médias de produção de massa fresca dos tratamentos com plantas daninhas e cultura do milho em que se utilizou $P$. maximum, $B$. brizantha e $B$. decumbens foram proporcionais a 90,11, 71,25 e $87,02 \%$ da produção média obtida em suas testemunhas, respectivamente (Tabela 3). A boa produtividade das plantas forrageiras no sistema, mesmo quando em competição com as plantas daninhas e com a cultura do milho, pode ser explicada em função de a 
semeadura ter sido realizada no mesmo dia da semeadura do milho, fato que permitiu às forrageiras maior acúmulo de massa fresca devido, provavelmente, a um menor efeito de competição interespecífica. Esses resultados corroboram aqueles demonstrados por Shelton \& Humphreys (1972) e Souza Neto (1993).

Outro aspecto que deve ser mencionado é que, possivelmente, o fato de a semeadura da cultura do milho e das culturas forrageiras ter sido realizada no mesmo dia conferiu às plantas forrageiras maior capacidade de supressão das plantas daninhas. Isso é resultado da rápida ocupação do nicho ecológico pelas forrageiras e, conseqüentemente, da diminuição dos recursos necessários ao crescimento e desenvolvimento das plantas daninhas. Essa situação confirma os resultados verificados e mencionados por Radosevich (1996) e Silva et al. (2004).

Nas Tabelas 4 e 5 estão apresentados todos os parâmetros do modelo logístico obtidos para as variáveis massa seca (g por planta) e área foliar $\left(\mathrm{cm}^{2}\right.$ por planta). Pôde-se verificar que a interferência do efeito das três espécies de plantas daninhas e da cultura do milho foi semelhante sobre a massa seca da cultura forrageira $B$. decumbens; no tratamento testemunha (B. decumbens sem a presença das plantas daninhas e da cultura do milho) a

Tabela 3 - Produção de massa fresca total das plantas forrageiras $\left(\mathrm{t} \mathrm{ha}^{-1}\right)$ na interação dos tratamentos com culturas forrageiras e plantas daninhas e na testemunha absoluta (sem a cultura do milho e sem plantas daninhas), aos 160 dias após a instalação do experimento. Piracicaba, 2004

\begin{tabular}{|l|c|c|c|c|}
\hline \multirow{2}{*}{ Planta forrageira } & \multicolumn{4}{|c|}{ Planta Daninha } \\
\cline { 2 - 5 } & I. grandifolia & A. hybridus & D. horizontalis & Testemunha $^{1 /}$ \\
\hline B. decumbens & $32,96^{2} / \mathrm{bB}$ & $32,25 \mathrm{bB}$ & $32,62 \mathrm{bB}$ & $37,47 \mathrm{cA}^{\prime}$ \\
B. brizantha & $33,01 \mathrm{bB}$ & $32,56 \mathrm{bB}$ & $32,34 \mathrm{bB}$ & $45,80 \mathrm{bA}$ \\
P. maximum & $56,07 \mathrm{aB}$ & $56,18 \mathrm{aB}$ & $56,71 \mathrm{aB}$ & $63,24 \mathrm{aA}$ \\
\hline CV\% & \multicolumn{4}{|c|}{12,50} \\
\hline
\end{tabular}

${ }^{1 /}$ Ausência da cultura do milho e de plantas daninhas; ${ }^{2 /}$ Médias seguidas pela mesma letra na linha (maiúscula) e na coluna (minúscula) não diferem estatisticamente entre si pelo teste de Tukey a $5 \%$ de probabilidade.

Tabela 4 - Parâmetros do modelo logístico ${ }^{1 /}$ para a variável acúmulo de massa seca (g por planta) das espécies forrageiras crescendo na presença da cultura do milho e das diferentes plantas daninhas utilizadas no experimento e para a testemunha absoluta (sem a cultura do milho e sem plantas daninhas). Piracicaba, 2004

\begin{tabular}{|c|c|c|c|c|c|c|c|}
\hline & \multirow{2}{*}{\multicolumn{2}{|c|}{ Tratamento }} & \multicolumn{5}{|c|}{ Parâmetro } \\
\hline & & & \multirow{2}{*}{$\frac{\mathrm{a}}{0,305}$} & \multirow{2}{*}{$\frac{b}{21,900}$} & \multirow{2}{*}{$\frac{\mathrm{c}}{55,550}$} & \multirow{2}{*}{$\frac{\mathrm{d}}{-13,104}$} & \multirow{2}{*}{$\begin{array}{c}\mathrm{R}^{2} \\
0,998\end{array}$} \\
\hline \multirow{9}{*}{ Milho } & \multirow{3}{*}{ IAQGR } & B. decumbens & & & & & \\
\hline & & B. brizantha & 2,116 & 60,882 & 81,707 & $-9,586$ & 0,984 \\
\hline & & P. maximum & 1,176 & 58,402 & 84,071 & $-8,552$ & 0,994 \\
\hline & \multirow{3}{*}{ AMACH } & B. decumbens & 0,001 & 22,478 & 58,491 & $-7,253$ & 0,997 \\
\hline & & B. brizantha & 3,284 & 59,211 & 84,417 & $-17,742$ & 0,987 \\
\hline & & P. maximum & 0,751 & 60,795 & 85,862 & $-8,031$ & 0,990 \\
\hline & \multirow{3}{*}{ DIGHO } & B. decumbens & 0,011 & 22,779 & 56,236 & $-7,746$ & 0,995 \\
\hline & & B. brizantha & 2,684 & 60,953 & 83,165 & $-13,889$ & 0,990 \\
\hline & & P. maximum & 1,145 & 60,093 & 84,451 & $-10,275$ & 0,996 \\
\hline \multirow{3}{*}{\multicolumn{2}{|c|}{ Testemunha }} & B. decumbens & 0,162 & 47,076 & 69,657 & $-5,765$ & 0,989 \\
\hline & & B. brizantha & 1,807 & 65,163 & 79,680 & $-9,585$ & 0,995 \\
\hline & & $P$. maximum & 1,474 & 64,727 & 79,578 & $-10,491$ & 0,995 \\
\hline
\end{tabular}

${ }^{1 /}$ Modelo: $y=a+\left(b /\left(1+(x / c)^{d}\right)\right)$. 
Tabela 5 - Parâmetros do modelo logístico ${ }^{1 /}$ para a variável acúmulo de área foliar $\left(\mathrm{cm}^{2}\right.$ por planta) das espécies forrageiras crescendo na presença da cultura do milho e das diferentes plantas daninhas utilizadas no experimento e para a testemunha absoluta (sem a cultura do milho e sem plantas daninhas). Piracicaba, 2004

\begin{tabular}{|c|c|c|c|c|c|c|c|}
\hline & \multirow{2}{*}{\multicolumn{2}{|c|}{ Tratamento }} & \multicolumn{5}{|c|}{ Parâmetro } \\
\hline & & & \multirow{2}{*}{$\frac{a}{18,018}$} & \multirow{2}{*}{$\frac{b}{772,467}$} & \multirow{2}{*}{$\frac{\mathrm{c}}{53,225}$} & \multirow{2}{*}{$\frac{d}{-8,125}$} & \multirow{2}{*}{$\frac{\mathrm{R}^{2}}{0,995}$} \\
\hline \multirow{9}{*}{ Milho } & \multirow{3}{*}{ IAQGR } & B. decumbens & & & & & \\
\hline & & B. brizantha & 156,701 & 1371,258 & 82,297 & $-12,545$ & 0,960 \\
\hline & & P. maximum & 144,693 & 1883,264 & 83,902 & $-11,790$ & 0,974 \\
\hline & \multirow{3}{*}{$\mathrm{AMACH}$} & B. decumbens & 764,064 & $-718,065$ & 55,990 & 69,708 & 0,982 \\
\hline & & B. brizantha & 175,080 & 1421,669 & 83,842 & $-12,868$ & 0,948 \\
\hline & & P. maximum & 115,234 & 1951,255 & 81,102 & $-8,329$ & 0,968 \\
\hline & \multirow{3}{*}{ DIGHO } & B. decumbens & $-5,725$ & 886,251 & 62,801 & $-3,380$ & 0,966 \\
\hline & & B. brizantha & 120,497 & 1512,167 & 80,959 & $-8,649$ & 0,971 \\
\hline & & P. maximum & 188,772 & 1835,583 & 85,829 & $-21,293$ & 0,969 \\
\hline \multirow{3}{*}{\multicolumn{2}{|c|}{ Testemunha }} & B. decumbens & 21,233 & 1744,840 & 79,357 & $-3,822$ & 0,965 \\
\hline & & B. brizantha & 137,451 & 1777,040 & 80,476 & $-10,926$ & 0,974 \\
\hline & & P. maximum & 25,912 & 2267,099 & 61,423 & $-2,916$ & 0,955 \\
\hline
\end{tabular}

${ }^{1 /}$ Modelo: $y=a+\left(b /\left(1+(x / c)^{d}\right)\right)$.

espécie acumulou aproximadamente o dobro da quantidade de massa seca em relação aos demais tratamentos. O efeito da interferência das plantas daninhas e da cultura do milho sobre $B$. decumbens foi mais pronunciado a partir dos 60 dias aproximadamente (Figura 1).

$\mathrm{O}$ acúmulo de massa seca obtido pela planta forrageira $B$. brizantha (Figura 2) indica que os efeitos competitivos da cultura do milho e das plantas daninhas foram pouco pronunciados, quando comparados com a testemunha desta espécie. Assim, B. brizantha pode ser considerada uma cultura forrageira adequada para o sistema de consórcio, devido à sua alta competitividade neste sistema. Em relação à cultura forrageira $P$. maximum, com os resultados apresentados na Figura 3, verifica-se que a espécie possui boa competitividade neste sistema de produção. Pode-se observar que os três tratamentos onde havia a cultura do milho e plantas daninhas apresentaram efeitos semelhantes, embora na testemunha (P. maximum crescendo sem a presença das plantas daninhas e sem a cultura do milho) o acúmulo de massa seca (g por planta) tenha sido maior que nos outros três tratamentos. No entanto, pelos resultados apresentados na Figura 3, pode-se inferir que $P$. maximum, em razão de sua eficiência competitiva, pode ser indicado para este sistema de consorciação.

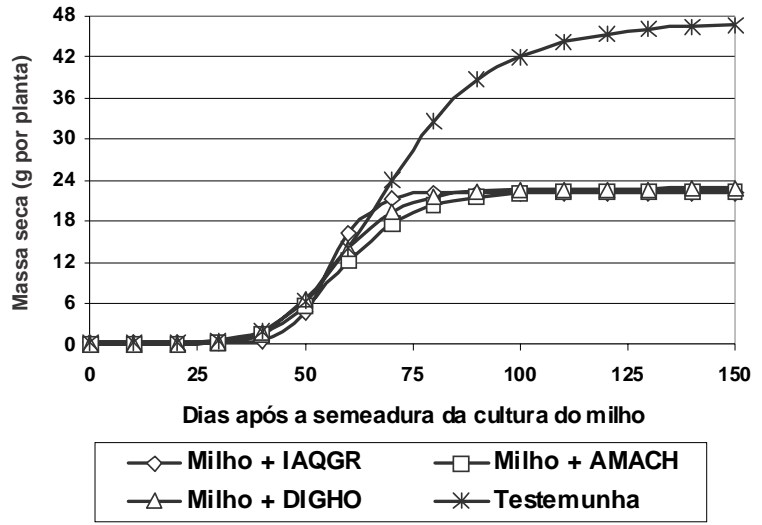

Figura 1 - Acúmulo de massa seca pela planta forrageira Brachiaria decumbens quando na presença da cultura do milho e de diferentes plantas daninhas e na testemunha absoluta (sem a cultura do milho e sem plantas daninhas). Piracicaba, 2004.

Os dados de acúmulo de área foliar $\left(\mathrm{cm}^{2}\right.$ por planta) reforçam a discussão estabelecida para a variável massa seca, em que, novamente, a presença das plantas daninhas e da cultura do milho reduziu a formação de folhas das três plantas forrageiras em diferentes magnitudes. A espécie B. decumbens mostrouse a mais sensível à competição interespecífica, e as espécies $B$. brizantha e $P$. maximum apresentaram-se como mais tolerantes (Figuras 4, 5 e 6). 


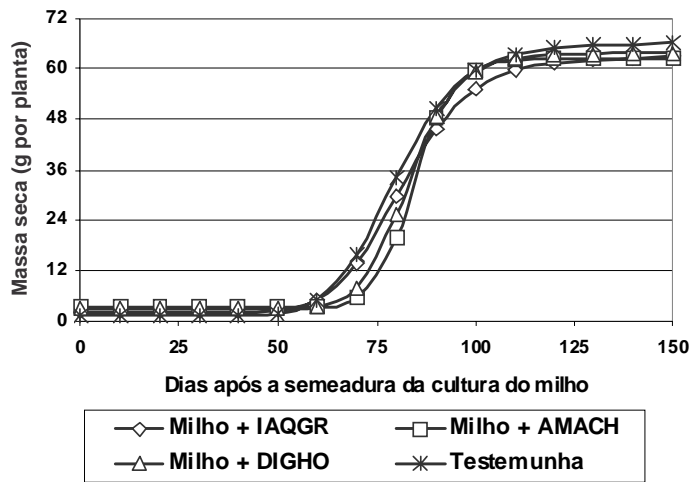

Figura 2 - Acúmulo de massa seca pela planta forrageira Brachiaria brizantha quando na presença da cultura do milho e de diferentes plantas daninhas e na testemunha absoluta (sem a cultura do milho e sem plantas daninhas). Piracicaba, 2004.

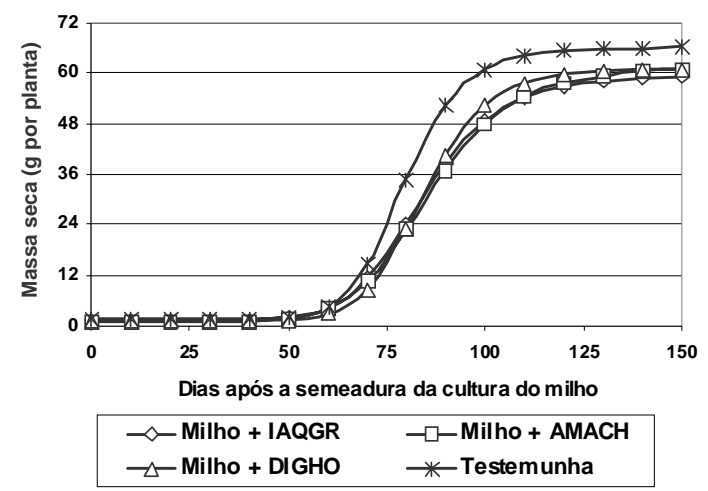

Figura 3 - Acúmulo de massa seca pela planta forrageira Panicum maximum quando na presença da cultura do milho e de diferentes plantas daninhas e na testemunha absoluta (sem a cultura do milho e sem plantas daninhas). Piracicaba, 2004.

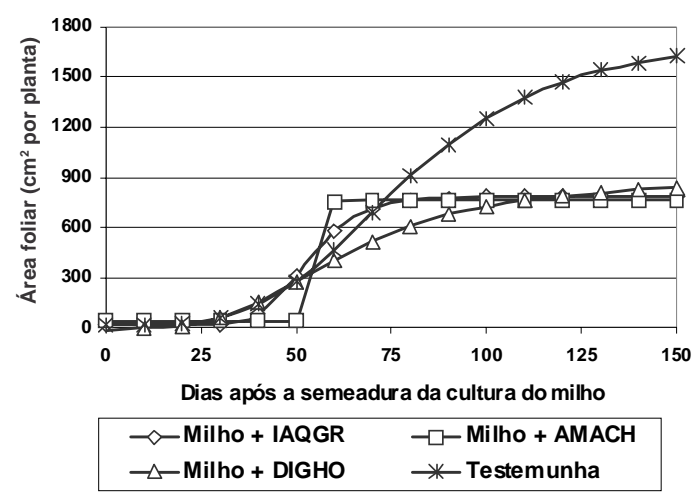

Figura 4 - Acúmulo de área foliar pela planta forrageira Brachiaria decumbens quando na presença da cultura do milho e de diferentes plantas daninhas e na testemunha absoluta (sem a cultura do milho e sem plantas daninhas). Piracicaba, 2004.

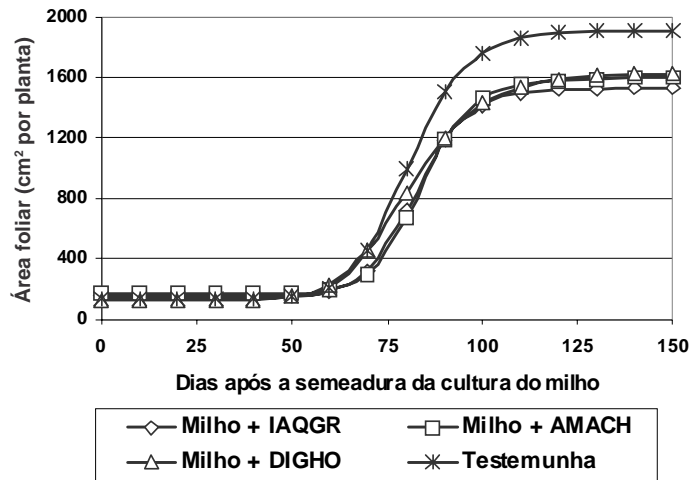

Figura 5 - Acúmulo de área foliar pela planta forrageira Brachiaria brizantha quando na presença da cultura do milho e de diferentes plantas daninhas e na testemunha absoluta (sem a cultura do milho e sem plantas daninhas). Piracicaba, 2004.

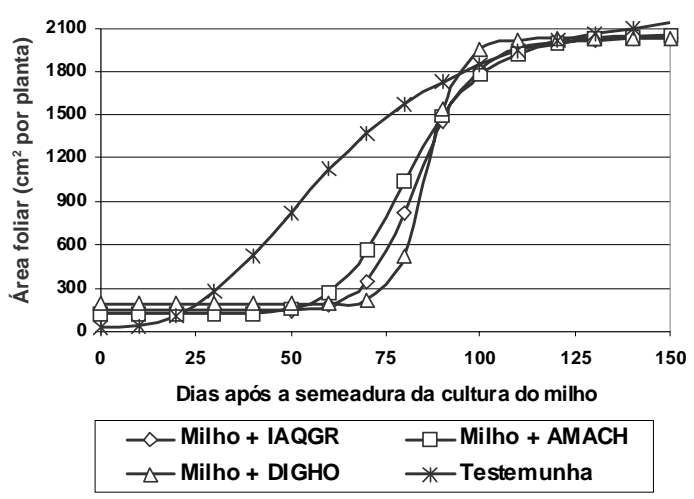

Figura 6 - Acúmulo de área foliar pela planta forrageira Panicum maximum quando na presença da cultura do milho e de diferentes plantas daninhas e na testemunha absoluta (sem a cultura do milho e sem plantas daninhas). Piracicaba, 2004.

Os resultados reforçam a teoria segundo a qual se acredita que a planta forrageira, quando estabelecida em consórcio, mantém seu crescimento mesmo com o sombreamento ocasionado pelo milho. Esse fato provavelmente contribui para a supressão da infestação das plantas daninhas devido ao efeito de competição e/ou alelopatia, uma vez que as plantas forrageiras possuem boa plasticidade fenotípica quanto à captura de radiação em resposta ao sombreamento e, por conseqüência, a capacidade de manter o crescimento mesmo com restrição de luz (Dias Filho, 2000).

Com base nos resultados deste experimento, pode-se concluir que: a espécie forrageira Brachiaria decumbens foi a menos eficiente

Planta Daninha, Viçosa-MG, v. 24, n. 1, p. 45-52, 2006 
quanto à habilidade de competição interespecífica; e as forrageiras Brachiaria brizantha e Panicum maximum foram as espécies que mais produziram massa fresca, podendo-se inferir que foram as plantas menos prejudicadas pela somatória das interferências negativas da cultura do milho e das plantas daninhas estudadas, de forma que foram consideradas eficientes no sistema de consórcio.

\section{LITERATURA CITADA}

BENINCASA, M. M. P. Análise de crescimento de plantas, noções básicas. 2.ed. Jaboticabal: UNESP/FUNEP, 2003. $41 \mathrm{p}$.

BROCH, D. L.; PITOL, C.; BORGES, E. P. Integração agricultura-pecuária: plantio direto da soja sobre pastagem na integração agropecuária. Maracaju: FUNDAÇÃO MS para Pesquisa e Difusão de Tecnologias Agropecuárias, 1997. 24 p. (FUNDAÇÃO MS, Informativo Técnico, 01/97).

BULISANI, E. A.; BRAGA, N. R.; ROSTON, A. J. Utilização de leguminosas como cobertura de solo em sistemas de adubação verde ou rotação de culturas. In: ENCONTRO PAULISTA DE PLANTIO DIRETO, 1., 1987, Piracicaba. Resumos... Piracicaba: FEALQ/USP, 1987. p. 63-70.

CHRISTOFFOLETI, P. J.; MENDONÇA, C. G. Controle de plantas daninhas na cultura de milho: enfoque atual. In: FANCELLI, A. L.; DOURADO NETO, D. Milho: tecnologia e produtividade. Piracicaba: ESALQ/USP/LPV, 2001. 259 p.

COLOZZI FILHO, A. et al. Alterações na biomassa microbiana do solo e em alguns de seus componentes, em função da adubação verde do cafeeiro. In: SIMPÓSIO DE PESQUISA DOS CAFÉS DO BRASIL, 1., 2000, Poços de Caldas: 2000. v. 2. p. 1393-1395.

DIAS FILHO, M. B. Growth and biomass allocation of the C4 grasses Brachiaria brizantha and Brachiaria humidicola under shade. Pesq. Agropec. Bras., v. 35, n. 12, p. 2335-2341, 2000.

EMPRESA BRASILEIRA DE PESQUISA AGROPECUÁRIA - EMBRAPA. Sistema brasileiro de classificação de solos. Brasília: 1999. 412 p.
KÖPPEN, W. Climatologia: con un estudio de los climas de la tierra. México: Fondo de Cultura Económica, 1948. $478 \mathrm{p}$.

RADOSEVICH, S. Physiological aspects of competition. In: Weed ecology. 2.ed. New York: John Wiley and Sons, 1996. p. 217-301.

SEEFELDT, S. S.; JENSEN, J. E.; FUERST, E. P. Loglogistic analysis of herbicide dose-response relationship. Weed Technol., v. 9, p. 218-227, 1995.

SEVERINO, F. J. Efeitos de diferentes adubos verdes na supressão de plantas daninhas e seletividade de herbicidas. 2000. 120 f. Dissertação (Mestrado em Agronomia) Escola Superior de Agricultura "Luiz de Queiroz", Piracicaba, 2000.

SHELTON, H. M.; HUMPHREYS, L. R. Pasture establishment in upland rice crops at Na Pheng, Central Laos. Tropical Grassl., v. 6, n. 3, p. 223-228, 1972.

SILVA, A. A.; JAKELAITIS, A.; FERREIRA, L. R. Manejo de plantas daninhas no Sistema Integrado AgriculturaPecuária. In: ZAMBOLIM, L.; SILVA, A. A.; AGNES, E. L. Manejo integrado: integração agricultura-pecuária. ViçosaMG: UFV, 2004. p. 117-170.

SOUZA NETO, J. M. Época de plantio e adubação de Brachiaria brizantha cv. Marandu e espaçamento do milho como cultura acompanhante, na formação de pastagens. 1993. 58 f. Dissertação (Mestrado em Agronomia) - Escola Superior de Agricultura "Luiz de Queiroz", Piracicaba, 1993.

WILLEY, R. W. Intercropping - Its importance and research needs. Part. 1. Competition and Yield advantages. Field Crops Abstr., v. 42, n. 1, p. 1-10, 1979.

WUTKE, E. B. Adubação verde: manejo da fitomassa e espécies utilizadas no Estado de São Paulo. In: WUTKE, E. B.; BULISANI, E. A.; MASCARENHAS, H. A. I Curso sobre adubação verde no IAC. Campinas: IAC, 1993. p. 17-30. (Documentos - IAC, 35).

WUTKE, E. B. Desempenho do feijoeiro em rotação com milho e adubos verdes. 1998. $146 \mathrm{f}$. Tese (Doutorado em Agronomia) - Escola Superior de Agricultura "Luiz de Queiroz”, Piracicaba, 1998. 